\title{
Chemiresistive $\mathrm{H}_{2} \mathrm{O}_{2}$ gas sensors based on graphene decorated with $\mathrm{Cu}_{2} \mathrm{O}$ nanowires and a protective PVP layer
}

\author{
Oleksandr Ovsianytskyi ${ }^{1,2}$, Oleksii Ohiienko ${ }^{3}$, Yun S. Nam4, Oh Young-Jei ${ }^{3}$, Aleksander Gurlo², Kang \\ B. Lee $^{1}$ \\ ${ }^{1}$ Green City Technology Institute, Korea Institute of Science and Technology, \\ Hwarang-ro 14 gil 5, Seoul 02792, Republic of Korea \\ 2 Fachgebiet Keramische Werkstoffe / Chair of Advanced Ceramic Materials, Technische Universitaet \\ Berlin, Berlin 10623, Germany \\ ${ }^{3}$ Opto-electronic materials and devices research center, Korea Institute of Science and Technology \\ Hwarang-ro 14 gil 5, Seoul 02792, Republic of Korea \\ ${ }^{4}$ Computational Science Center, Korea Institute of Science and Technology \\ Hwarang-ro 14 gil 5, Seoul 02792, Republic of Korea \\ Email: O.Ovsianytskyi@ceramics.tu-berlin.de
}

\begin{abstract}
:
In this study, we demonstrate $\mathrm{H}_{2} \mathrm{O}_{2}$ gas sensing with a single-layer graphene decorated with $\mathrm{Cu}_{2} \mathrm{O}$ nanowires $\left(\mathrm{Cu}_{2} \mathrm{ONWs}\right)$ and a protective PVP layer. Single-layered graphene was grown using chemical vapor deposition (CVD) technique, the $\mathrm{Cu}_{2} \mathrm{ONWs}$ were synthesized hydrothermally. The composite has been characterized using AFM, SEM, EDS, XPS and TEM. The average diameter of $\mathrm{Cu}_{2} \mathrm{ONWs} 35$ nanometers with (111) and (220) crystallographic planes. The functionalization of graphene with $\mathrm{Cu}_{2} \mathrm{ONWs}$ nanowires has modified the electronic properties of graphene, achieving a drastic resistivity change in the presence of $\mathrm{H}_{2} \mathrm{O}_{2}$ gas. This allows for real-time monitoring of low levels (below $1 \mathrm{ppm}$ ) of $\mathrm{H}_{2} \mathrm{O}_{2}$ at ambient temperature with a fast response and recovery time.
\end{abstract}

Key words: CVD graphene, chemiresistive sensors, $\mathrm{H}_{2} \mathrm{O}_{2}$ sensing, copper oxide nanowires.

\section{Introduction}

Hydrogen peroxide $\left(\mathrm{H}_{2} \mathrm{O}_{2}\right)$ is one of the strongest oxidizers known, being used as a disinfectant and a bleaching agent. A concentration of 75 ppm is considered to be immediately dangerous to human life and the safe concentration is typically $<1 \mathrm{ppm}$. Therefore, the detection of low levels of $\mathrm{H}_{2} \mathrm{O}_{2}$ gas is a crucial issue for the keeping the working personal safe from harmful hydrogen peroxide vapors.

Our goal was to develop an efficient, costeffective, highly sensitive and selective sensor for real-time monitoring of $\mathrm{H}_{2} \mathrm{O}_{2}$ gas. We have chosen graphene for this study since it can be produced in large quantities with good repeatability of results, and it is very stable under harsh environments and can effectively work under room temperature.

Recent DFT (Density Functional Theory) calculations revealed that pristine graphene is not suitable for proper $\mathrm{H}_{2} \mathrm{O}_{2}$ detection, but defects can slightly improve its sensing ability
$[1]$

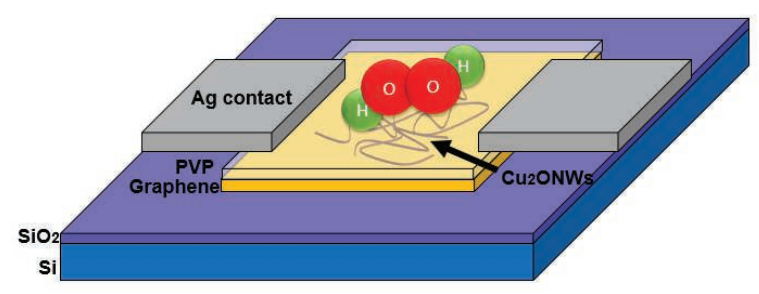

Fig. 1. Schematic representation of the sensor studied in this work

Furthermore, doping with transitional metals can drastically increase graphene sensitivity towards $\mathrm{H}_{2} \mathrm{O}_{2}$ gas. Particularly, $\mathrm{Ag}$ and $\mathrm{Cu}$ provide -3.94 and $-4.01 \mathrm{eV}$ binding energies with towards hydrogen peroxide, respectively, [2]. Thus, our goal was to develop an effective sensor according to these theoretical investigations.

\section{Experimental}

Monolayer graphene was grown using typical CVD route on the $25 \mu \mathrm{m}$ thick $\mathrm{Cu}$ foil which was 
chemically cleaned from contaminations and oxides. After the synthesis process, the monolayer graphene was transferred onto $\mathrm{Si} / \mathrm{SiO}_{2}$ substrate.

$\mathrm{Cu}_{2} \mathrm{ONWs}$ were hydrothermally synthesized from a mixture of $\mathrm{EG}$ with $\mathrm{CuCl}$ and $\mathrm{NaCl}$. The resulting precipitation was cleaned several times with acetone and chlorobenzene. Subsequently, $\mathrm{Cu}_{2} \mathrm{ONWs}$ were dispersed with IPA and mixed with PVP which is well known for its surface protective applications [3]. Finally, for the preparation of "doped" graphene sensors the $\mathrm{Cu}_{2} \mathrm{ONWs-PVP}$ solution was placed onto graphene-Si/SiO 2 substrate using a spin-coating method and baked for $30 \mathrm{~min}$ at $80^{\circ} \mathrm{C}$.

\section{Results and discussion}

We used a common chemiresistive approach to detect gaseous $\mathrm{H}_{2} \mathrm{O}_{2}$. Thus, the concentrations of our analyte can be quantified by measuring the change of sensor's resistance as a function of time. Fig. 2 represents the reference response of a pristine graphene and a graphene-

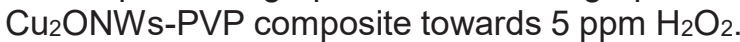

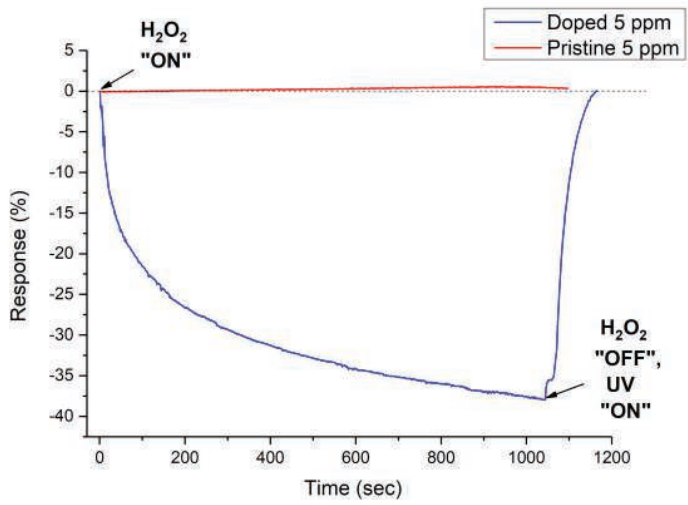

Fig. 2. Doped and pristine sample response towards $5 \mathrm{ppm} \mathrm{H}_{2} \mathrm{O}_{2}$ gas.

The resistance change of graphene doped with $\mathrm{Cu}_{2} \mathrm{ONWs}$ was observed to be $-37 \%$ after 1000 sec exposure time in comparison to $+0.5 \%$ of pristine graphene. Our graphene- $\mathrm{Cu}_{2} \mathrm{ONWs-}$ PVP composite sensor has shown relatively fast relaxation time ( 100-200 sec) under $254 \mathrm{~nm}$ UV light illumination. Sensor's response as a function of $\mathrm{H}_{2} \mathrm{O}_{2}$ concentration is presented in the Fig. 3, with the response measuring time decreasing for higher concentrations ( $1000 \mathrm{sec}$ for 1-5 ppm and $\sim 850 \mathrm{sec}$ for $25 \mathrm{ppm}$ ).

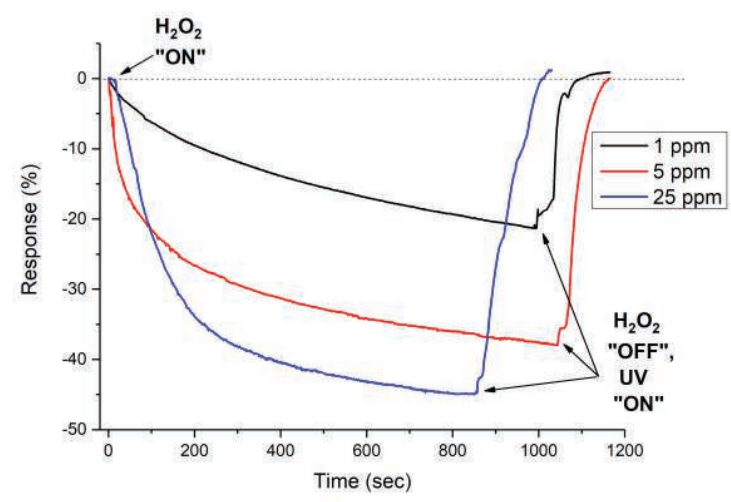

Fig. 3. Sensor's response to different $\mathrm{H}_{2} \mathrm{O}_{2}$ concentrations.

\section{Conclusion}

This study shows that a graphene- $\mathrm{Cu}_{2} \mathrm{ONWs-}$ PVP composite can be a suitable choice for sensing gaseous $\mathrm{H}_{2} \mathrm{O}_{2}$. The comparison between pristine and doped samples has shown a dramatic increase in the response value. The PVP protective layer prevents access of $\mathrm{H}_{2} \mathrm{O}$ from the atmosphere to the surface of the sensor, which can lead to involuntary the formation of hydroxides on the surface of the sensor, as well as averts other contaminations.

\section{References}

[1] G. Luque, M. Rojas, G. Rivas, E. Leiva, The origin of the catalysis of hydrogen peroxide reduction by functionalized graphene surfaces: A density functional theory study, Electrochimica Acta, 56 (2010), 523-530,

DOI:10.1016/j.electacta.2010.09.016

[2] D. Düzenli, A Comparative Density Functional Study of Hydrogen Peroxide Adsorption and Activation on the Graphene Surface Doped with $\mathrm{N}$, $\mathrm{B}, \mathrm{S}, \mathrm{Pd}, \mathrm{Pt}, \mathrm{Au}, \mathrm{Ag}$, and $\mathrm{Cu}$ Atoms, J. Phys. Chem. C, 120 (2016), 20149-20157, DOI: 10.1021/acs.jpcc.6b06131

[3] J. Yan, G. Zou, A. Wu, J. Ren, A. Hu, N. Zhou, Polymer-Protected Cu-Ag Mixed NPs for LowTemperature Bonding Application, Journal of Elec. Mater. 41 (2012), 1886, DOI:10.1007/s11664-0122008-7 